\title{
Análise Da Taxa De Mortalidade Hospitalar Em Um Hospital Público Universitário Com A Complexidade Hospitalar Em Relação Às Regiões Do Brasil
}

\author{
Valente, A.P.; Toralles, E.K.; Butzke, B.L.; Jiménez, L.F.; Cittolin-Santos, G.F.; \\ Marimon, M.M.; Kluck, M.M.;
}

Apresentador: Amanda Prestes Valente

\section{Resumo}

Introdução: Cada vez um número maior de pacientes necessita de internação em hospitais terciários. Este fato se deve a diversos fatores, incluindo o maior acesso da população ao sistema de saúde, o avanço no manejo das doenças crônicas, com o consequente aumento na sobrevida desses pacientes e a disponibilização de tratamentos multimodais agressivos, com potenciais complicações que necessitam monitoração ou manejo hospitalar. Paralelamente, avanços nos cuidados resultaram em melhorias substanciais na sobrevida de pacientes com doenças e complicações críticas variadas.

Métodos: Comparamos as taxas de mortalidade e de letalidade hospitalar por capítulo do CID- 10 entre o Hospital de Clínicas de Porto Alegre (HCPA), conforme registrado em prontuário eletrônico, e os hospitais de média e baixa complexidade, analisando o uso da mortalidade hospitalar como indicador de qualidade assistencial. Foram utilizados os dados da região sul e da região nordeste, sendo equivalentes, respectivamente, a um hospital de média e de baixa complexidade. Os dados do HCPA foram obtidos do Sistema de Informações Gerenciais (IG) do hospital, e as informações referentes aos demais foram retiradas do DATASUS. Resultados: As taxas de mortalidade hospitalar no ano de 2013 foram de
4,7\% no HCPA, 4,2\% na região sul e 3,3\% na região nordeste. O HCPA apresentou maiores taxas de letalidade em doenças graves, como neoplasias, que são a maior causa isolada de óbito no HCPA, representando $12,1 \%$, ao passo que na região sul estão em segundo lugar, representando $8,3 \%$, e no nordeste estão em quarto lugar, representando apenas $6,1 \%$. Quanto às doenças do aparelho circulatório, a taxa de letalidade foi de $6,8 \%$ no HCPA, $6,6 \%$ na região sul e $8,1 \%$ na região nordeste, enquanto a letalidade por gravidez, parto e puerpério foi a menor causa entre os 3 grupos analisados, sendo 0,01\%, 0,01\% e $0,03 \%$ respectivamente. Conclusão: O HCPA é uma referência em tratamento oncológico, o que explica a maior letalidade por neoplasia no HCPA em comparação às regiões sul e nordeste. Já a baixa letalidade por gravidez, parto e puerpério está em concordância com as taxas encontradas nas demais regiões e em países em desenvolvimento. Além da qualidade assistencial, outras variáveis que influenciam as taxas de mortalidade hospitalar devem ser analisadas em conjunto. A gravidade dos pacientes internados está diretamente relacionada a complexidade hospital, podendo gerar maiores taxas de letalidade intra-hospitalar.

\section{Referência:}

Valente, A.P.; Toralles, E.K.; Butzke, B.L.; Jiménez, L.F.; Cittolin-Santos, G.F.; Marimon, M.M.; Kluck, M.M.;. Análise Da Taxa De Mortalidade Hospitalar Em Um Hospital Público Universitário Com A Complexidade Hospitalar Em Relação Às Regiões Do Brasil. In: II Congresso Brasileiro de Medicina Hospitalar - II CBMH [= Blucher Medical Proceedings, vol.1, num.5] São Paulo: Editora Blucher, 2014. p.28

DOI 10.5151/medpro-II-cbmh-020 